\title{
Neurophysiological Effects of Dry Needling in Patients with Neck Pain, A Randomized Clinical Trial
}

\author{
Luis Martín-Sacristán \\ University of Alcalá \\ Cesar Calvo-Lobo \\ Complutense University of Madrid \\ Daniel Pecos-Martín \\ University of Alcalá \\ Josue Fernández-Carnero ( $\nabla$ josue.fernandez@urjc.es ) \\ King Juan Carlos University \\ Jose Luis Alonso-Pérez \\ European University of Madrid
}

\section{Research Article}

Keywords: deep dry needling (DDN), pressure pain threshold, MTrPs in patients with neck pain

Posted Date: August 6th, 2021

DOI: https://doi.org/10.21203/rs.3.rs-709500/v1

License: (c) (1) This work is licensed under a Creative Commons Attribution 4.0 International License. Read Full License 


\section{Abstract}

The purpose was to determine the efficacy of deep dry needling (DDN) applied on an active myofascial trigger point (MTrP) versus a latent-MTrP versus a non-MTrP location, on pain reduction and cervical disability, in patients with chronic neck pain. A randomized, double-blind clinical trial design was used. A sample of 65 patients was divided into non-MTrP-DDN, active-MTrP-DDN and latent-MTrP-DDN groups. The visual analog scale (VAS), reproduction of the patient's pain, number of local twitch responses, pressure pain threshold (PPT) and Neck Disability Index (NDI) were assessed before, during and after the intervention and up to 1 month post-intervention. The active-MTrP-DDN-group reduced pain intensity more than non-MTrP-DDN-group after a week and a month $(p<0.01)$. Active-MTrP-DDN-group showed the greatest improvement in tibialis muscle PPT. An association was found with a higher percentage of subjects in whom their neck pain was reproduced when the active-MTrP (77.3\%) and the latent-MTrP (81.8\%) were treated. The application of DDN on an active-MTrP in the upper trapezius muscle shows greater improvements in pain intensity after one week and one month post-intervention, as well as lesser improvement in PPT in the tibialis muscle, compared to DDN applied in latent-MTrPs or outside of MTrPs in patients with neck pain

\section{Introduction}

Neck pain is the fourth leading cause of disability, with an annual prevalence rate exceeding $30 \%$. In the world, around $70 \%$ of the population will have neck pain throughout their lives, while the prevalence in Spain is $19.5 \%$. $(1,2)$. Most cases of acute neck pain seem to resolve with or without treatment, but up to $50 \%$ of people who have it may continue feeling pain or have frequent episodes $(2-4)$.

Among the muscles of the neck, the upper trapezius is the muscle that most frequently presents the trigger point syndrome of the whole body due to its permanent activity and micro-trauma (5).

The prevalence of neck pain is higher in women than in men. In addition, there are several important factors that are related to the appearance of neck pain, especially those related to work, stress and depression (1). In relation to work, neck pain appears more frequently in those jobs which involving prolonged static postures and repetitive movements of the upper limbs (6).

On the other hand, it has been proposed that MTrPs could be responsible for the appearance of pain in patients with mechanical neck pain; therefore, other studies include MTrP therapy for the management of these patients (7).

The prevalence of MTrPs in patients with myofascial pain was $93.75 \%$ for the upper trapezius muscle, being the most prevalent muscle for MTrPs presence. Within the same, the prevalence of active MTrP was higher on the right side with $82.1 \%$ while on the left side it was $79 \%$ (4).

Myofascial pain syndrome is defined as a hypersensitive spot in a taut band of a skeletal muscle and referred pain and can be diagnosed by the presence of one or more myofascial trigger points 
(MTrPs) $(8,9)$.

MTrPs are clinically classified as active or latent. Active MTrPs are those that cause spontaneous pain or pain during movement, stretching or compression. Latent MTrPs are usually asymptomatic, but they reproduce pain or discomfort when they are compressed $(6,9)$.

Other typical symptoms associated with MTrPs in addition to local and referred pains are the appearance of muscle weakness and a restricted range of motion. In the case of active and latent MTrPs, they elicit a local twitch response and pain that reproduces the patient's symptoms $(9,10)$. The combination of these symptoms could have a large impact on the quality of life, mood, and health status (6).

The treatment of myofascial pain is based on the inactivation of MTrPs, above all through a manual technique or through the invasive technique known as dry needling (DN) (11). There are two types of DN. The first type is the superficial DN, which penetrates only the skin, and second, deep DN (DDN), which involves inserting a solid filiform needle directly into the MTrP and through the muscle. $(12,13)$.

Traditionally, the effectiveness of dry needling has been related to the provocation of the local twitch response (LTR). The LTR is characterized by a visible contraction of part of the taut band in the involved muscle upon mechanical stimulation with needling to a sensitive site in a MTrP region. Although there is debate about this, some authors suggest that MTrP DN is most effective if a local twitch response (LTR) is elicited during the procedure (14). The needle is moved up and down with or without withdrawal from the muscle tissue to elicit LTRs (15). Although there is a lack of knowledge about the mechanisms of dry needling, some studies support that LTR is crucial to achieve the elimination of pro-nociceptive and proinflammatory substances. However, in clinical practice, even when LTR is induced, there is not always a positive effect (16).

Some studies have shown the benefit of applying dry needling to an active trigger point in the trapezius muscle producing greater improvements in pain measured with visual analogue scale (VAS), pain pressure threshold (PPT) and levels of disability produced by neck pain (17).

In relation to the mechanisms of action of $\mathrm{DN}$, some factors were involved in the activation of the central nervous system, complex endogenous pain modulating mechanisms and activation of the autonomic nervous system to produce electromyographic changes in the MTrPs. This supposes a possible action on the etiopathogenesis of MTrPs, which could justify motor effects, beyond the purely sensitive ones $(18,19)$. There is a sympathetic interaction with myofascial tension that demonstrates the facilitating contribution of sympathetic hyperactivity to mechanical sensitization, and the possible underlying mechanisms of local and referred muscle pain (20).

Moreover, vasoconstriction, cold skin, sweating, and pilomotor response in patients with pain due to active PGM may be related to sympathetic hyperactivity. The vasoconstrictor activity of the SNS was activated by nociceptive stimulation of latent PGM (21). Finally, other study identifies the neuromuscular 
junction as a target of the sympathetic nervous system and shows that sympathetic input is crucial for the maintenance and function of the synapse (22).

It is also important to decide the dose of DN treatment. Some studies explains that the greater the number of "in-and-outs" with the needle in the muscle, the greater the post-needling pain appears, but, in turn, the better results seem to be found when six or more LTRs are achieved $(23,24)$. On the other hand, other study indicates that performing DN without eliciting LTRs has superiority over the DN along with eliciting LTR while the treatment aimed to receive long-term effects (5).

Therefore, the aim of this study was to determine the efficacy of DDN applied on an active MTrP versus a latent MTrP versus a non-MTrP location, on pain reduction, mechanical hyperalgesia and cervical disability, in patients with chronic neck pain attributable to myofascial pain syndrome. The second aim was to evaluate the association between number of LTR and improvement and the association between reproduce the patient's pain during dry needling with the improvement following dry needling.

\section{Materials And Methods}

Study Design. A randomized, double-blind clinical trial design was used for the study. Patients were randomly allocated to one of three different intervention groups (Non-MTrP group, Active-MTrP group, and Latent-MTrP group) performed by a computer-generated random-sequence table created before the start of the study with Epidat 4.2 software (Epidemiology Service of the General Directorate of Health Public of the Consellería de Sanidade (Xunta de Galicia) with the support of the Pan American Health Organization (PAHO-WHO) and the CES University of Colombia) (25).

All subjects signed an informed consent, and the study was approved by the Ethics Committee for Animal Research and Experimentation at the University of Alcalá with the number identification CEID/HU/2018/41.

The study was guided by the Consolidated Standards of Reporting Trials (CONSORT) statement and included the CONSORT checklist.

This study was registered at NIH U. S. National Library of Medicine ClinicalTrials.gov under identifier (NCT number): NCT03345238. The study start date was registered on 13/03/2017 and the study completion date was registered on 10/08/2019.

Participants. Participants were recruited from a Primary Health Care Centre in Alcalá de Henares (Madrid, Spain) and the University community from the University of Alcalá. Patients with neck pain of muscular origin were referred and screened for possible eligibility criteria.

In this research we defined neck pain as mechanical pain in the cervical muscles, which can be provoked both by maintained postures and by movements. Patients were selected if they met all of the following criteria: 
- Non-specific neck pain, unilateral or bilateral.

- Neck pain $\geq 3$ months of duration.

- Presence of active and latent MTP in the upper, left, right or bilateral trapezius muscle, in relation to the patient's neck pain (26).

The recent clinical criteria recommended identifying active and latent $\operatorname{MTrPs}(8,17,23,27)$, such as taut band palpable, a hypersensitive spot at the pressure of a taut band, referred pain and the reproduction of any of the symptoms experienced by a patient and the recognition of pain (to identify an active MTrP).

In order to meet the criteria to participate in the study, patients had to pass an initial physical examination performed by a single investigator to rule out the exclusion criteria:

- Unsurpassed fear of needles.

- Coagulation disorders.

- Specific alterations of the cervical region in the clinical history.

- Infiltration of corticosteroids or local anaesthetics during a year before the study.

- Surgical intervention of the cervical region or previous shoulder.

- Skin lesions in the area, as well as infection or inflammation.

- Taking analgesic, anti-inflammatory or anticoagulant medication the week before the study.

- Treatment of MTrP or DDN in the neck region in the 6 months prior to the intervention.

- Cognitive deficit in the medical history.

Patients were between 18 and 65 years of age (28). Each participant received a thorough explanation about the content and purpose of the treatment before signing an informed consent form relative to the procedures.

Masking. Participants were randomized into each intervention group without knowing which of the three groups they belonged to.

Likewise, the physiotherapist who carried out the interventions treated all the participants without knowing in which group each one of them was.

\section{Outcome Measurement}

Primary outcome measures. The primary outcome measures were neck pain intensity before, during and after intervention, the association between reproduce the patient's pain during dry needling with the 
improvement following dry needling and the association between the number of local twitch responses and improvement.

Pain intensity. Neck pain intensity was measured before, during, immediately after intervention and the follow up was at 1, 6, 12, 24, 48, 72 hours after intervention and also 1 week and 1 month after intervention.

A visual analogue scale (VAS) was used, which is a well-established and validated self-report to measure the intensity of pain. It consists of a $100 \mathrm{~mm}$ line in which 0 indicates no pain and 100 indicate the worst pain imaginable by the patient. The patients should indicate where their pain is generally located within the measure described above. The VAS presented a moderate to good reliability (intraclass correlation coefficient 0.60 to 0.77 ) for the assessment of disability in patients with chronic musculoskeletal pain (29).

Patient's neck pain recognition. The association between the DDN site and the provocation of the patient's neck pain was assessed by asking the subjects of each group if their pain was reproduced and recognized during the intervention and the answers were collected as a dichotomous variable (yes / no).

Number of local twitches responses (LTRs). The LTRs number was evaluated by the physiotherapist who performed the intervention on an " $n$ " number of up to 12 dry needling ins and outs in the trapezius muscle $(n / 12)(5,17,23,24)$.

Secondary outcome measures. The secondary outcomes were neck disability and pressure pain threshold.

Neck disability. The validated Spanish version of the Neck Disability Index (NDI) was used to assess the degree of disability before, 1 week and 1 month after the intervention. The NDI is a valid tool for the measurement of pain and self-assessment of cervical disability. The NDI is composed of 10 questions related to daily functional activities. Each of the sections (intensity of neck pain, personal care, weight lifting, reading, headache, ability to concentrate, work capacity, driving, sleep and leisure activities) offers 6 possible answers that represent 6 levels progressive functional capacity, and it is scored from 0 to 5 ( 0 $=$ no disability, $5=$ total disability). The total score is expressed as a percentage of the maximum possible. A score between 5 and 14 represents a mild disability, whereas a score between 15 and 24 is interpreted as a moderate disability. Neck Disability Index scores $>25$ reflect a severe disability and the maximum score is 50 . NDI presents an acceptable reliability with an intraclass correlation coefficient (ICC) ranging from 0.50 to $0.98(30)$.

Pressure Pain Threshold (PPT). PPT was evaluated using a digital algometer. Pressure pain is defined as the minimum pressure that induces pain or discomfort with a $1 \mathrm{~cm} 2$ rubber disc. The results serve as a reference for the clinical diagnosis of abnormal sensitivity and for documentation of treatment results in the MPS. Pressure is applied at a rate of $1 \mathrm{~kg} / \mathrm{sec}$. Three consecutive tests were performed on the active, 
latent and non MTrP at 30 second intervals before and immediately after the intervention. Intra-evaluator reliability is high in the upper trapezius muscle $(I C C=0.94-0.97)(31)$.

Procedures and intervention. Participants were randomly assigned to the non-MTrP group or to the active MTrP group or to the latent MTrP group using randomization. Each participant was informed about the study and filled in the informed consent sheet as well as the data sheet and the NDI. After collecting the information from the participant, the evaluating therapist performed the physical evaluation of the patient and determined the major dry needling site according to the assigned group where the practitioner therapist performed dry needling intervention. Participants did not know which group they belonged to. Next, the practitioner therapist performed the dry needling intervention without knowing the group to which each participant was assigned, and again the evaluating therapist performed the post-intervention evaluations. One session of intervention were performed in each patient.

Patients were followed up for up to one month according to each measurement variable.

Detection of active or latent MTrPs or non-MTrPs. The MTrP was evaluated following the recommended clinical criteria to identify active and latent MTrPs, such as palpable taut band, exquisite local pain under the pressure of a taut band node, recognition by the patient of his usual pain when pressing the sensitive node (to identify an active MTrP), and referred pain. It is considered positive when 2 of the clinical criteria are found (8).

To the non-MTrP site, a $2 \mathrm{~cm}$ of distance to any other MTrP active or latent was selected in the trapezius muscle (17).

Dry needling. Patients were asked to lie in a supine position with the arms next to the body. Dry needling was performed with a $0.30 \times 30 \mathrm{~mm}$ DN needle (APS Regular Agupunt) with a guiding tube. The valuator therapist palpated the MTrPs in experimental groups and $2 \mathrm{~cm}$ separated of the MTrP in non-MTrPs group and then the practitioner therapist inserted the needle through the skin. Consecutively, the taut band was needled forward and backward until the exact punction point. Precise needling of the MTrPs elicited a brief contraction followed by relaxation of the muscle fibers; this is known as a LTR. Needling of the MTrP or the non-MTrP was repeated until 12 in and outs at a frequency of 12 hertz $(2,17,23,24)$.

Statistical Analysis. Data were analyzed using SPSS Statistics for Windows, version 25.0 (IBM, Armonk, NY, USA) was used for statistical analysis. A Kolmogorov-Smirnov test was used to test normality and no statistically differences were founded. A descriptive analysis was selected to summarize the outcomes in the 2 measurements in all groups (active MTrP DN group, latent MTrP DN group and non-MTrP DN group) and were included the mean, SD. A one-way ANOVA with the factor group (active MTrP DN, latent MTrP DN, and non-MTrP DN) was performed.

Repeated-measures analysis of variance (ANOVA) was performed considering the significance of the Greenhouse-Geisser correction when the Mauchly test rejected the sphericity to compare the differences between the 3 groups in the baseline. To analyze the contrast between the three treatment groups we 
used the ANOVA of repeated measures with 2 factors, 3 (groups) $\times 2$ times (pre and post), only the pain intensity variable was analyzed in the interaction with the group factor the 11 times (pre, during, post, 1 hour, 6 hour, 12 hours, 24 hours, 48 hours, 72 hours, 1 week and 1 month) to include the calculation of the effect size, the partial eta ( $\eta 2$ ) coefficient was used.

Moreover, multivariate regression analyses were carried out using linear regression analyses by the stepwise selection method in order to predict the differences of the outcome measurements at different moments with respect to baseline which showed between-groups statistically significant differences in the prior described analyses. These outcome measurements (VAS, PPT trapezius, PPT tibialis Muscle, PPT expansion and Neck disability index) were considered as dependent variables. Independent variables were descriptive data, local twitch responses (LTR), patient's pain recognition, group and the other outcome measurements at baseline. $\mathrm{F}$ probability was considered according to $\mathrm{a} \mathrm{P}$ in $=0.05$ and $\mathrm{P}$ out $=$ 0.10 .

All analyses were carried out "per intent-to-treat." Moreover, a P-value lower than 0.05 was considered as statistically significant for a $95 \%$ confidence interval $(\mathrm{Cl})$.

Simple size. A total sample size of at least 18 subjects per group had to be recruited based on an a priori power analysis (G*Power 3.1.9.2 from the University of Düsseldorf). This power analysis was performed for the within-between interaction in a repeated measures analysis with 3 groups, 11 measurements (baseline, measurements during intervention, immediately after the intervention and measurements after $1,6,12,24,48,72$ hours, 1 week and 1 month), a minimum power of 0.95 , an effect size of 0.3 and an a level of 0.05 .

\section{Results}

Clinical characteristics of the participants. Sixty five participants were assessed for eligibility (Figure 1). All subjects met the inclusion criteria. Therefore, sixty-five patients were included, of which 21 for the control group (Non-MTrP group), 22 for the Experimental group 1 (Dry needling in active-MTrP group), and 22 for the Experimental group 2 (Dry needling in latent-MTrP group).

Pain intensity. The ANOVA showed a significant effect for time ( $\left.F=306.099 ; P<0.0001 ; h_{p}{ }^{2}=0.834\right)$ and demonstrated a significant interaction between group and time $\left(F=3.117 ; P=0.0001 ; h_{p}{ }^{2}=0.093\right)$ for changes in intensity of the neck pain, data presented in Table 2. Post hoc analysis showed that the DDN active MTrP group exhibited greater pain post intervention than non-MTrP group (outside to the MTrP) and DDN in latent MTrP group within the first hour post dry needling but not the rest of the times measured $(P<0.01)$. Furthermore, 1 week after needling, the DDN in active MTrP group showed lower pain scores than the non-MTrP group with DDN outside, see Figure 2.

Statistically significant intra-group differences were found in the non-MTrP group and in the active trigger point dry needling group from one hour post dry needling to one month of follow-up and in the latent trigger point dry needling groups in the immediate post dry needling period $(p<0.01)$. 
Pressure pain threshold over trapezius muscle. The ANOVA showed a significant effect for time $\left(F=57.607 ; P<0.0001 ; h_{p}{ }^{2}=0.482\right)$ but not statistically significant interaction between group and time were found $\left(F=0.157 ; P=0.855 ; h_{p}{ }^{2}=0.005\right)$ for changes in PPT in the neck, data presented in Table 3. See Figure 3.

Pressure pain threshold over tibialis muscle. The ANOVA showed a significant effect for time ( $F=59,488$; $\left.P<0.0001 ; h_{p}{ }^{2}=0.490\right)$ and demonstrated a significant interaction between group and time $(F=5.786$; $\left.P=0.005 ; h_{p}{ }^{2}=0.157\right)$ for changes in PPT of the tibialis muscle, data presented in Table 4. Post hoc analysis showed that the $\mathrm{DN}$ active group exhibited lesser increase of pressure pain threshold post intervention than non-MTrP group (outside to the MTrP) and DN in latent group $(P<.05)$, see Figure 4.

Pressure pain threshold expansion. The ANOVA showed a significant effect for time ( $F=79.842$; $\left.P<.0001 ; h_{p}{ }^{2}=0.563\right)$ but not statistically significant interaction between group and time were found $\left(F=0.202 ; P=0.818 ; h_{p}{ }^{2}=0.006\right)$ for changes in PPT summation expansion, data presented in Table 5. See Figure 5.

3.6. Neck Disability Index. The ANOVA showed a significant effect for time $(F=131.775$; $P<.0001 ; h_{p}{ }^{2}=0.680$ ) but not statistically significant interaction between group and time were found $\left(F=0.098 ; P=0.933 ; h_{p}{ }^{2}=0.003\right)$ for changes in disability, data presented in Table 6. See Figure 6.

Association between the number of local twitch responses and pain provoked. There is no association that the higher the number of LTRs, the higher the percentage of subjects with moderate to severe neck pain ( $p>0.05$ ), but there is a statistically significant association with a chi-square, the higher the number of LTRs with the higher percentage of subjects in whom their neck pain is reproduced $(p<0.05)$.

A greater association of a greater number of LTRs was found in the active and latent trigger point dry needling groups $(p<.0001)$, than in the non-MTrP group.

Association between the dry needling site and the provocation of your neck pain. In addition, we found an association of a higher percentage of subjects in which their neck pain is reproduced when dry needling was done at the active trigger point $(77.3 \%)$ and in the latent $(81.8 \%)(p<0.001)$. However, no model was found in the prediction that producing their neck pain during dry needling produces a greater improvement in any of the variables measured.

\section{Multivariate regression analyses}

Prediction model for the PPT in tibialis difference during DN versus baseline. PPT over tibialis muscle after DN with respect to baseline showed a statistically significant predicted model by bleeding after DN and place of dry needling $\left(R^{2}=0.218 ; \beta=-2.356 ; F_{[.051]}=4.061 ; P<0.05\right)$, indicating a prediction of higher mechanical hyperalgesia over tibialis muscle difference after versus before $D N$ under the bleeding and 
site of dry needling (latent or active) difference. The rest of independent variables were excluded from the prediction model according to $\mathrm{F}$ probability $(\mathrm{P}$ in $=0.05$, $\mathrm{P}$ out $=0.10)$.

Prediction model for the Pain intensity difference at 1 week after DN versus baseline. Pain intensity difference at 1 week after DN with respect to baseline showed a statistically significant prediction model which was predicted by local twitch response $(L T R)$ and side treated $\left(R^{2}=0.157 ; \beta=-6.561 ; F_{[1,63]}=4.410\right.$; $P<0.001$ ), indicating a prediction of lower difference at 1 week after $D N$ versus baseline under less LTRs and under side treated. The rest of independent variables were excluded from the prediction model according to $\mathrm{F}$ probability $(\mathrm{P}$ in $=0.05, \mathrm{P}$ out $=0.10)$.

\section{Discussion}

According to our study findings, pain intensity, disability and mechanical hyperalgesia were improved equally in all points that were treated with deep dry needling in the muscle, regardless of whether it was in a trigger point, latent or in an area where there is no trigger point. In terms of pain, it was seen that immediately post-treatment, the group that was received dry needling on the active trigger point, presented a worsening, but the group with the active trigger point was the one with the greatest reduction in pain at one week. In terms of mechanical hyperalgesia at a distance (tibialis muscle), the group with dry needling on the active trigger point had the least improvement.

Some previous works by Pecos Martín et al (17) have studied the importance of treating the specific site that produces pain. In the case of the present investigation, in addition to the specific site and its relationship with the patient's symptomatology, if we achieve a greater number of LTRs, we will be able to reproduce the patient's pain during the intervention and ensure that we are needling active MTrPs. In those cases, we will achieve better results in the short term for our patients. Otherwise, some studies indicate that performing DN without eliciting LTRs presented superiority over the DN along with eliciting LTR while the treatment aimed to receive long-term effects (5).

Our results are consistent with another study in which dry needling was applied to the lumbar multifidus muscles in patients with low back pain. The presence of LTR did not produce a greater improvement in pain, disability, function and pain threshold to pressure at one week, although immediately the patients who had a LTR did have a greater improvement in function and pain threshold to pressure at one week (32).

We can therefore observe that a local twist response during dry needling is not a synonym for successful treatment.

One of the initial studies comparing DN versus lidocaine infiltration found conflicting results to ours, showing that mechanical hyperalgesia, pain intensity and range of motion improved more in the group that presented local twist responses than the group that did not (14). Although there are certain methodological limitations to this study, other researchers also suggest that the LTR produces a greater improvement (33). 
Additionally, in the results obtained, we have been able to observe how this type of intervention produces not only an improvement in pain perception, but also in the pressure pain threshold and neck disability at short term. According to these findings, we found several articles that, making other approaches, but evaluating the same and other variables, also found improvements until the short term (17,34-37).

These findings are in part supported by the results of a study that found that pain relief correlated with LTR, but only when pain intensity was high (38).

In relation with the pain intensity results, there is a greater soreness decrease after 1 week and 1 month, especially in the active MTrP group, as has been observed in previous studies, even over 2 points on the VAS scale when needling is done in the upper trapezius muscle $(28,39-41)$.

This study showed a significant effect for time but not statistically significant interaction between group and time were founded for changes in PPT in the upper trapezius.

On the other hand the DDN active group obtains a lesser improvement in PPT in the tibialis muscle, compared to performing DDN in latent trigger points or outside of trigger points in patients with neck pain.

It has relation with other previous studies where researchers showed that PPT levels increase when DNN is done in an active MTrP (39) and it could be a greater increase indeed after 2 days of the intervention (42). The results obtained from mechanical hyperalgesia are in accordance with the conclusions of a recent systematic review which concluded that dry needling produces an increase in the pain threshold to pressure (43).

In a previous study by Llamas-Ramos et al found that 2 sessions of dry needling produced a $73 \%$ increase in the pain threshold to pressure which was maintained for 2 weeks during follow-up (44) and in a study of Pecos-Martin et al. the research found that dry needling on the active trigger point resulted in an increase in PPT of $53.5 \%$, whereas dry needling outside the trigger point did not produce the same increase (17).

Cerezo Tellez et al. found an improvement of 4 points in PPT that was maintained for 6 months, being clinically relevant in patients with neck pain who applied 3 sessions of puncture, and in our study we only obtained an improvement of $4.87 \%$ (45). A possible explanation as to why other studies have found changes with a greater effect may be due to the number of sessions, or in the case of Pecos-Martin, because the puncture was performed on the lower trapezius muscle despite only one session (17).

The Neck Disability Index showed that all groups improved equally; therefore we can say that for the improvement of disability it does not matter where you perform the dry needling. The three groups have an improvement after 1 week and 1 month. This results are comparable to other studies where no differences were found between groups (24). 
The association between the number of local twitch responses and pain provoked showed that there is no association that the higher the number of LTRs, the higher the percentage of subjects with moderate to severe neck pain $(p>0.05)$. Regardless of the method used, there is considerable agreement that elicitation of a LTR produces more immediate and long-lasting pain relief than no elicitation of LTR, although some still believe that eliciting an LTR is not necessary for improvement. There is a statistically significant association with a chi-square, the higher the number of LTRs with the higher the percentage of subjects in whom their neck pain is reproduced $(p<0.05)$ but there is no association that for more LTRs there is a greater improvement, higher LTRs also occur more where there is an active trigger point than latent but that is not related to a greater improvement either. The production of single or multiple LTRs during muscular MTrP DN seems to have poor correlation in the short-term for the outcomes of pain and disability in patients with neck pain (46). The twitch response during dry needling might be clinically relevant, but should not be considered necessary for successful treatment (32). Other study found a higher number of patients with neck pain improvements superior to the moderate clinically important differences were observed when eliciting 6 LTRs and LTRs until exhaustion compared with not eliciting LTRs (23). In relation with long-term effects interventions, DN without eliciting LTR has superiority over the DN along with eliciting LTR (5).

A greater association of a greater number of LTRs was found in the active and latent trigger point dry needling groups $(p<.0001)$, than in the non-MTrP group.

And the association between the dry needling site and the provocation of the neck pain of the patients, we found an association of a higher percentage of subjects in which their neck pain is reproduced when dry needling is applied at the active trigger point $(77.3 \%)$ and in the latent $(81.8 \%)(p<0.001)$. This finding has relation to one of the clinical criteria recommended to identify active and latent MTrPs, which is the appearance of LTRs, in this case, during the intervention (8-10).

However, there was not any model in the prediction that producing their neck pain during dry needling produces a greater improvement in any of the variables measured.

Although it is probably the least known mechanism, the truth is that it is the only one capable of explaining some of the effects that are frequently observed when using the DDN, such as the decrease in tension of the taut band and the consequent gain mobility. The rest of the mechanisms could explain the decrease in pain and the elevation of the pressure pain threshold that is usually observed in studies with DDN techniques as well as this current study. However, the known capacity of the autonomic nervous system to produce electromyographic changes in the MTrPs supposes of a possible action on the etiopathogenesis of MTrPs, which could justify motor effects, beyond the purely sensitive ones.

According to Hong, $(47,48)$ the formation of the MTrP and the taut band is controlled by the central nervous system through a "MTrP circuit" and, thus, stimulation with a needle can transmit a strong signal to the central nervous system to induce the powerful reflex of the LTR that will help to reorganize the control that the central nervous system exercises over the MTrP and the tight band, breaking the vicious circle of the "MTrP circuit". 
For all these reasons, it is essential to expand knowledge in basic research in order to continue making new findings in the experimental and clinical field that make us take not only a step, but also a leap in improving the treatment of our patients.

\section{Limitations}

The current study has some limitations. We suggest that this study could be done on a larger sample size to provide more insight regarding the variables effects. The second is that we assess and treat the upper trapezius muscle in a single session, although other muscles may be involved in neck pain. Furthermore, the trapezius is one of the most intolerant to puncture and this prevents the results obtained from being extrapolated to dry needling in other muscles. Third, our study measured short-term effects; therefore, future studies should investigate the medium and long-term effects of deep dry needling by performing several treatment sessions on various muscles or by adding different locations of the same.

\section{Clinical and Research Implications}

The present study offers an idea of how to manage better the treatment of MTrPs using the DDN technique. Knowing a little more about the behavior of pain in relation to the place where we perform the technique, we can address the problems of our patients with more efficient treatments.

According to this study, patients have grater improvement if the physiotherapist applies the DDN technique in an active MTrP in relation with pain intensity but only for the first week, but not for a month, which means that in the short term it doesn't matter where you do the dry needling.

A greater contribution is necessary in this line of work in which the sample of participants is increased, as well as the number of sessions to be carried out, the muscles treated and a longer-term follow-up.

\section{Conclusions}

Deep dry needling of the trapezius muscle, regardless of whether it is on a trigger point, latent or nontrigger point area, produces the same positive effects in improving pain intensity, discomfort and local mechanical hyperalgesia, and the number of local twist responses and patient pain reproduction are not associated with improvement. In terms of mechanical hyperalgesia at a distance (tibialis muscle), the group with dry needling on the active trigger point had the least improvement.

There is no association between the number of LTR and improvement and reproducing the patient's pain during dry needling with the improvement of the patient.

It seems that precise location is not necessary when applying dry needling in clinical practice, but more studies need to be carried out with larger sample sizes, applying more sessions and with longer follow-ups. 


\section{Declarations}

Author Contributions: Conceptualization, L.M.-S., J.F.-C., C.C.-L. and D.P.-M.; methodology, L.M.-S., J.F.-C., C.C.-L. and D.P.-M.; software L.M.-S.; formal analysis, J.F.-C., C.C.-L.; investigation, L.M.-S., J.F.-C., C.C.-L. and D.P.-M.; resources, L.M.-S., J.F.-C., C.C.-L. and D.P.-M.; data curation, J.F.-C., C.C.-L.; writing-original draft preparation, L.M.-S., J.F.-C., C.C.-L. and D.P.-M.; writing-review and editing, L.M.-S., J.F.-C., C.C.-L., D.P.-M. and J.L.A.-P.; visualization, L.M.-S.; supervision, J.F.-C., C.C.-L. and D.P.-M.. All authors have read and agreed to the published version of the manuscript.

Funding: This research received no external funding.

Institutional Review Board Statement: The study was conducted according to the guidelines of the Declaration of Helsinki, and approved by the Ethics Committee of the University of Alcalá (CEID/HU/2018/41).

Informed Consent Statement: Informed consent was obtained from all subjects involved in the study. Written informed consent has been obtained from the patient(s) to publish this paper.

Conflicts of Interest: The authors declare no conflict of interest.

\section{References}

1. Verhagen AP. Physiotherapy management of neck pain. J Physiother [Internet]. 2021;67(1):5-11. Available from: https://doi.org/10.1016/j.jphys.2020.12.005

2. Navarro-Santana MJ, Sanchez-Infante J, Fernández-de-las-Peñas C, Cleland JA, Martín-Casas P, Plaza-Manzano G. Effectiveness of Dry Needling for Myofascial Trigger Points Associated with Neck Pain Symptoms: An Updated Systematic Review and Meta-Analysis. J Clin Med. 2020;9(10):3300.

3. SP C. Epidemiology, diagnosis, and treatment of neck pain. Mayo Clin Proc. 2015;90(2):284-99.

4. Cerezo-Téllez E, Torres-Lacomba M, Mayoral-del Moral O, Sánchez-Sánchez B, Dommerholt J, Gutiérrez-Ortega C. Prevalence of myofascial pain syndrome in chronic non-specific neck pain: A population- based cross-sectional descriptive study. Pain Med (United States). 2016;17(12):2369-77.

5. Hakim IK, Takamjani IE, Sarrafzadeh J, Ezzati K, Bagheri R. The effect of dry needling on the active trigger point of upper trapezius muscle: Eliciting local twitch response on long-term clinical outcomes. J Back Musculoskelet Rehabil. 2019;32(5):717-24.

6. De Meulemeester KE, Castelein B, Coppieters I, Barbe T, Cools A, Cagnie B. Comparing Trigger Point Dry Needling and Manual Pressure Technique for the Management of Myofascial Neck/Shoulder Pain: A Randomized Clinical Trial. J Manipulative Physiol Ther [Internet]. 2017;40(1):11-20. Available from: http://dx.doi.org/10.1016/j.jmpt.2016.10.008 
7. Vernon $\mathrm{H}$, Humphreys $\mathrm{K}$, Hagino $\mathrm{C}$. Chronic mechanicalneck pain in adults treated by manual therapy: a systematicreview of change scores in randomized clinical trials. JManipulative Physiol Ther. 2007;30:215-27.

8. Fernández-de-las-Peñas C, Dommerholt J. International Consensus on Diagnostic Criteria and Clinical Considerations of Myofascial Trigger Points: A Delphi Study. Pain Med. 2018 Jan;19(1):142-50.

9. Simons D, Travell J, Simons L. Myofascial Pain and Dysfunction. The Trigger Point Manual. 3rd ed. Philadelphia, PA: Wolters Kluwer; 2019.

10. Li L, Stoop R, Clijsen R, Hohenauer E, Fernández-de-Las-Peñas C, Huang Q, et al. Criteria Used for the Diagnosis of Myofascial Trigger Points in Clinical Trials on Physical Therapy: Updated Systematic Review. Clin J Pain. 2020;36(12):955-67.

11. Cummings $M$, Baldry P. Regional myofascial pain: diagnosis and management. Best Pr Res Clin Rheumatol. 2007;21(2):367-87.

12. Kalichman L, Vulfsons S. Dry needling in the management of musculoskeletal pain. J Am Board Fam Med. 2010;23(5):640-6.

13. Baldry P. Superficial versus deep dry needling. Acupunct Med. 2002;20(2-3):78-81.

14. Hong C. Lidocaine injection versus dry needling to myofascial trigger point: the importance of the local twitch response. Am J Phys Med Rehabil. 1994;73(4):256-63.

15. Dunning J, Butts R, Mourad F, Young I, Flannagan S, Perreault T. Dry needling: a literature review with implications for clinical practice guidelines. Phys Ther Rev. 2014;19(4):252-65.

16. Shah JP, Danoff J V, Desai MJ, Parikh S, Nakamura LY, Phillips TM, et al. Biochemicals associated with pain and inflammation are elevated in sites near to and remote from active myofascial trigger points. Arch Phys Med Rehabil. 2008 Jan;89(1):16-23.

17. Pecos-Martín D, Montañez-Aguilera FJ, Gallego-Izquierdo T, Urraca-Gesto A, Gómez-Conesa A, Romero-Franco N, et al. Effectiveness of dry needling on the lower trapezius in patients with mechanical neck pain: A randomized controlled trial. Arch Phys Med Rehabil. 2015;96(5):775-81.

18. Gerwin R, Dommerholt J, Shah J. An expansión of Simons' integrated hypothesis of trigger point formation. Curr Pain Headache Rep. 2004;8(6):468-75.

19. Hsieh $Y$, Chou $L$, Joe $Y$, Hong $C$. Phentolamine effect on the spontaneous electrical activity of active loci in a myofascial trigger spot of rabbit skeletal muscle. Arch Phys Med Rehabil. 2011;92(7):1098-105.

20. Ge H, Fernández-de-las-Peñas C, Arendt-Nielsen L. Sympathetic facilitation of hyperalgesia evoked from myofascial tender and trigger points in patients with unilateral shoulder pain. Clin Neurophysiol. 
2006;117(7):1545-50.

21. Kimura Y, Ge H, Zhang Y, Kimura M, Sumikura H, Arendt-Nielsen L. Evaluation of sympathetic vasoconstrictor response following nociceptive stimulation of latent myofascial trigger points in humans. Acta Physiol. 2009;196(4):411-7.

22. Khan M, Lustrino D, Silveira W. Sympathetic innervation controls homeostasis of neuromuscular junctions in health and disease. Proc Natl Acad Sci. 2016;113(3):746-50.

23. Fernández-Carnero, J Gilarranz-de-Frutos L, León-Hernández J, Al E. Effectiveness of Different Deep Dry Needling Dosages in the Treatment of Patients With Cervical Myofascial Pain: A Pilot RCT. Am J Phys Med Rehabil. 2017;96(10):726-33.

24. Martín-Pintado-Zugasti, A Fernández-Carnero J, León-Hernández J, Al E. Postneedling Soreness and Tenderness After Different Dosages of Dry Needling of an Active Myofascial Trigger Point in Patients With Neck Pain: A Randomized Controlled Trial. PM R. 2018;10(12):1311-20.

25. Department of Health of the Autonomous Government of Galicia, (PAHO) P-AHO. EPIDAT: Epidemilogical Data Analysis [Internet]. 2014. Available from: http://dxsp.sergas.es/

26. Myburgh C, et al. Standardized manual palpation of myofascial trigger points in relation to neck/shoulder pain; the influence of clinical experience on inter-examiner reproducibility. Man Ther. 2011;16(2):136-40.

27. Abbaszadeh-Amirdehi M, Ansari N, Naghdi S, Olyaei G, Nourbakhsh M. Neurophysiological and clinical effects of dry needling in patients with upper trapezius myofascial trigger points. J Bodyw Mov Ther. 2017;Jan;21(1):48-52.

28. H. Gerber L, Shah J, Rosenberg W, et al. Dry Needling Alters Trigger Points in the Upper Trapezius Muscle and Reduces Pain in Subjects with Chronic Myofascial Pain. PM R. 2015;7(7):711-8.

29. Boonstra A, Schiphorst-Preuper H, Reneman M, Posthumus J, Stewart R. Reliability and validity of the visual analogue scale for disability in patients with chronic musculoskeletal pain. Int $\mathrm{J}$ Rehabil Res. 2008;Jun;31(2):165-9.

30. Andrade Ortega J, et al. Validación de una versión española del índice de discapacidad cervical. Med Clin. 2008;130(3):85-9.

31. Walton D, Macdermid J, Nielson W, Teasell R, Chiasson M, Brown L. Reliability, standard error, and minimum detectable change of clinical pressure pain threshold testing in people with and without acute neck pain. J Orthop Sport Phys Ther. 2011;41:644-50.

32. Koppenhaver S, Walker M, Rettig C, Davis J, Nelson C, Su J, et al. The association between dry needling-induced twitch response and change in pain and muscle function in patients with low back pain: 
a quasi-experimental study. Physiotherapy. 2017;103(2):131-7.

33. Tekin L, Akarsu S, Durmus O, Cakar E, Dincer U, Kiralp MZ. The effect of dry needling in the treatment of myofascial pain syndrome: a randomized double-blinded placebo-controlled trial. Clin Rheumatol. 2013;32:309-15.

34. Ziaeifar M, Arab A., Mosallanezhad, Z Nourbakhsh M. Dry needling versus trigger point compression of the upper trapezius: A randomized clinical trial with two-week and three-month follow-up. J Man Manip Ther. 2019;27:152-61.

35. Myburgh C, Hartvigsen J, Aagaard P, Holsgaard-Larsen A. A. Skeletal muscle contractility, selfreported pain and tissue sensitivity in females with neck/shoulder pain and upper Trapezius myofascial trigger pointsa randomized intervention study. Chiropr Man Ther. 2012;20:36.

36. Mejuto-Vázquez M., Salom-Moreno J, Ortega-Santiago R, Truyols-Domínguez S, Fernández-De-Laspeñas C. Short-Term changes in neck pain, widespread pressure pain sensitivity, and cervical range of motion after the application of trigger point dry needling in patients with acute mechanical neck pain: $A$ randomized clinical trial. J Orthop Sport Phys Ther. 2014;44:252-260.

37. Martín-Rodríguez A, Sáez-Olmo E, Pecos-Martín D, Calvo-Lobo C. C. Effects of dry needling in the sternocleidomastoid muscle on cervical motor control in patients with neck pain: A randomised clinical trial. Acupunct Med. 2019;37:151-163.

38. Kuan T, Hong C, Chen S, Tsai C, Yen W, Chen J, et al. Myofascial pain syndrome: correlation between the irritability of trigger points and the prevalence of local twitch responses during trigger point injection. J Musculoskelet Pain. 2012;20:250-6.

39. Cerezo-téllez E, Lacomba MT, Fuentes-gallardo I, Mayoral O, Rodrigo-medina B, Gutiérrez C. Dry needling of the trapezius muscle in office workers with neck pain: a randomized clinical trial. J Man Manip Ther [Internet]. 2016;24(4):1-10. Available from:

http://dx.doi.org/10.1179/2042618615Y.0000000004

40. Gerber LH, Sikdar S, Aredo J V, Shah JP. Beneficial Effects of Dry Needling for Treatment of Chronic Myofascial Pain Persist for 6 Weeks After Treatment Completion. Physiol Behav. 2017;176(3):139-48.

41. Garcia-de-Miguel S, Pecos-Martin D, Larroca-Sanz T, Sanz-de-Vicente B, Garcia-Montes L, FernandezMatias R, et al. Short-Term Effects of PENS versus Dry Needling in Subjects with Unilateral Mechanical Neck Pain and Active Myofascial Trigger Points in Levator Scapulae Muscle: A Randomized Controlled Trial. J Clin Med. 2020;9(6):1665.

42. Ziaeifar M, Arab AM, Nourbakhsh MR. Clinical Effectiveness of Dry Needling Immediately After Application on Myofascial Trigger Point in Upper Trapezius Muscle. J Chiropr Med [Internet]. 2016;15(4):252-8. Available from: http://dx.doi.org/10.1016/j.jcm.2016.08.009 
43. Lew J, Kim J, Nair P. Comparison of dry needling and trigger point manual therapy in patients with neck and upper back myofascial pain syndrome: a systematic review and meta-analysis. J Man Manip Ther. 2021;29(3):136-46.

44. Llamas-Ramos R, Pecos-Martín D, Gallego-Izquierdo, T Llamas-Ramos I, Plaza-Manzano G, OrtegaSantiago, R Cleland J, Fernández-de-Las-Peñas C. Comparison of the short-term outcomes between trigger point dry needling and trigger point manual therapy for the management of chronic mechanical neck pain: a randomized clinical trial. J Orthop Sport Phys Ther. 2014;44(11):852-61.

45. Cerezo-Téllez E, Torres-Lacomba , M Fuentes-Gallardo I, Perez-Muñoz M, Mayoral-Del-Moral, O LluchGirbés E, Prieto-Valiente L, Falla D. Effectiveness of dry needling for chronic nonspecific neck pain: a randomized, single-blinded, clinical trial. Pain. 2016;157(9):1905-17.

46. Perreault T, Dunning J, Butts R. The local twitch response during trigger point dry needling: Is it necessary for successful outcomes? J Bodyw Mov Ther [Internet]. 2017;21(4):940-7. Available from: https://doi.org/10.1016/j.jbmt.2017.03.008

47. Hong C. Considerations and recommendationsof myofascial trigger points injection. $\mathrm{J}$ Musculoskelet Pain. 1994;2(1):29-59.

48. Hsieh Y, Chou L, Joe Y, Hong C. Spinal cord mechanism involving the remote effects of dry needling on the irritability of myofascial trigger spots in the rabbit skeletal muscle. Arch Phys Med Rehabil. 2011;92(7):1098-105.

\section{Tables}

Table 1. Demographic and clinical characteristics at baseline 


\begin{tabular}{|c|c|c|c|c|}
\hline Demographics & $\begin{array}{l}\text { Non-MTrP } \\
(n=21)\end{array}$ & $\begin{array}{l}\text { Active-MTrP } \\
(\mathrm{n}=22)\end{array}$ & $\begin{array}{l}\text { Latent-MTrP } \\
(n=22)\end{array}$ & Value \\
\hline Age (years) & $27.90 \pm 13.02$ & $22.91 \pm 7.14$ & $28.45 \pm 16.22$ & 0.28 \\
\hline Sex (Women / Men) & $12 / 9$ & $12 / 10$ & $11 / 11$ & 0.89 \\
\hline BMI (kg m-2) & $22.96 \pm 3.34$ & $22.94 \pm 2.54$ & $22.95 \pm 2.31$ & 1.00 \\
\hline Place (UAH / PHCC) & $16 / 5$ & $22 / 0$ & $19 / 3$ & 0.58 \\
\hline Lateralization (right / left) & $16 / 5$ & $18 / 4$ & $17 / 5$ & 0.89 \\
\hline $\begin{array}{l}\text { IPAQ (Low / Medium / } \\
\text { High) }\end{array}$ & $2 / 10 / 9$ & $0 / 10 / 12$ & $0 / 11 / 11$ & 0.98 \\
\hline $\operatorname{VAS}(0-10 \mathrm{~cm})$ & $6.19 \pm 1.47$ & $6.91 \pm 1.44$ & $6.73 \pm 1.64$ & 0.28 \\
\hline $\begin{array}{l}\text { PPT in trapezius }(\mathrm{kg} / \\
\left.\mathrm{cm}^{2}\right)\end{array}$ & $2.84 \pm 0.95$ & $2.69 \pm 0.76$ & $2.90 \pm 0.91$ & 0.72 \\
\hline PPT in tibialis $\left(\mathrm{kg} / \mathrm{cm}^{2}\right)$ & $4.92 \pm 1.13$ & $5.39 \pm 1.36$ & $6.06 \pm 1.36$ & 0.01 \\
\hline NDI $(0-50)$ & $21.24 \pm 13.56$ & $20.68 \pm 11.62$ & $20.59 \pm 13.01$ & 0.98 \\
\hline
\end{tabular}

Values are expressed as the mean \pm standard deviation or number of participants.

Abbreviations: BMI: body mass index; UAH: University Alcalá Henares; PHCC: Primary Health Care Centre; IPAQ: International Physical Activity Questionnaire; VAS: Visual Analogue Scale; PPT: Pressure Pain Threshold; NDI: Neck Disability Index.

Table 2. Pain intensity outcome data and comparison between groups 


\begin{tabular}{|c|c|c|c|c|c|c|}
\hline Variable & Non-MTrP & Active-MTrP & Latent-MTrP & $\begin{array}{c}\text { Non-MTrP } \\
\text { vs } \\
\text { Active-MTrP }\end{array}$ & $\begin{array}{c}\text { Non-MTrP } \\
\text { vs } \\
\text { Latent-MTrP }\end{array}$ & $\begin{array}{c}\text { Active-MTrP } \\
\text { vs } \\
\text { Latent-MTrP }\end{array}$ \\
\hline VAS PRE & $6.19 \pm 1.47$ & $6.91 \pm 1.44$ & $6.73 \pm 1.64$ & $\begin{array}{c}-0.709 \\
(-1.875-0.457) \\
0.419\end{array}$ & $\begin{array}{c}-0.527 \\
(-1.693-0.639) \\
0.810\end{array}$ & $\begin{array}{c}0.182 \\
(-0.956-1.320) \\
1.000\end{array}$ \\
\hline VAS DURING & $6.65 \pm 1.63$ & $7.18 \pm 1.65$ & $6.77 \pm 1.54$ & $\begin{array}{c}-0.532 \\
(-1.755-0.691) \\
0.866\end{array}$ & $\begin{array}{c}-0.123 \\
(-1.346-1.100) \\
1.000\end{array}$ & $\begin{array}{c}0.409 \\
(-0.784-1.602) \\
1.000\end{array}$ \\
\hline VAS POST & $5.15 \pm 1.46$ & $6.84 \pm 2.33^{*}$ & $5.32 \pm 1.86$ & $\begin{array}{c}-1.691 \\
(-3.158--0.224) \\
0.019 *\end{array}$ & $\begin{array}{c}-0.168 \\
(-1.635-1.299) \\
1.000\end{array}$ & $\begin{array}{c}1.523 \\
(0.091-2.955) \\
0.033^{*}\end{array}$ \\
\hline VAS AT 1 HOUR & $3.75 \pm 2.07$ & $3.77 \pm 2.07$ & $3.09 \pm 1.27^{*}$ & $\begin{array}{c}-0.023 \\
(-1.419-1.373) \\
1.000\end{array}$ & $\begin{array}{c}0.659 \\
(-0.737-2.055) \\
0.749\end{array}$ & $\begin{array}{c}0.682 \\
(-0.680-2.044) \\
0.668\end{array}$ \\
\hline VAS AT 6 HOURS & $3.60 \pm 2.19$ & $3.27 \pm 1.78$ & $2.77 \pm 1.31$ & $\begin{array}{c}0.327 \\
(-1.026-1.680) \\
1.000\end{array}$ & $\begin{array}{c}0.827 \\
(-0.526-2.180) \\
0.412\end{array}$ & $\begin{array}{c}0.500 \\
(-0.820-1.820) \\
1.000\end{array}$ \\
\hline VAS AT 12 HOURS & $3.10 \pm 2.10$ & $2.50 \pm 1.26$ & $2.55 \pm 1.44$ & $\begin{array}{c}0.600 \\
(-0.635-1.835) \\
0.709\end{array}$ & $\begin{array}{c}0.555 \\
(-0.680-1.789) \\
0.820\end{array}$ & $\begin{array}{c}-0.045 \\
(-1.250-1.160) \\
1.000\end{array}$ \\
\hline VAS AT 24 HOURS & $2.35 \pm 2.30$ & $1.55 \pm 1.41$ & $2.00 \pm 1.51$ & $\begin{array}{c}0.805 \\
(-0.538-2.147) \\
0.436\end{array}$ & $\begin{array}{c}0.350 \\
(-0.992-1.692) \\
1.000\end{array}$ & $\begin{array}{c}-0.455 \\
(-1.692-0.992) \\
1.000\end{array}$ \\
\hline VAS AT 48 HOURS & $1.65 \pm 1.93$ & $0.86 \pm 1.13$ & $1.41 \pm 1.26$ & $\begin{array}{c}0.786 \\
(-0.326-1.899) \\
0.260\end{array}$ & $\begin{array}{c}0.241 \\
(-0.871-1.353) \\
1.000\end{array}$ & $\begin{array}{c}-0.545 \\
(-1.631-0.540) \\
0.662\end{array}$ \\
\hline VAS AT 72 HOURS & $0.70 \pm 1.03$ & $0.23 \pm 0.53$ & $0.73 \pm 1.20$ & $\begin{array}{c}0.473 \\
(-0.259-1.204) \\
0.350\end{array}$ & $\begin{array}{c}-0.027 \\
(-0.759-0.704) \\
1.000\end{array}$ & $\begin{array}{c}-0.500 \\
(-1.214-0.214) \\
0.269\end{array}$ \\
\hline VAS AT 1 WEEK & $0.50 \pm 0.83$ & $0.05 \pm 0.21^{*}$ & $0.36 \pm 0.58$ & $\begin{array}{c}0.455 \\
(0.008-0.901) \\
0.045^{*}\end{array}$ & $\begin{array}{c}0.136 \\
(-0.310-0.583) \\
1.000\end{array}$ & $\begin{array}{c}-0.318 \\
(-0.754-0.118) \\
0.232\end{array}$ \\
\hline VAS AT 1 MONTH & $0.20 \pm 0.52$ & $0.00 \pm 0.00$ & $0.05 \pm 0.32$ & $\begin{array}{c}0.200 \\
(-0.042-0.442) \\
0.138\end{array}$ & $\begin{array}{c}0.155 \\
(-0.087-0.396) \\
0.361\end{array}$ & $\begin{array}{c}-0.045 \\
(-0.281-0.190) \\
1.000\end{array}$ \\
\hline
\end{tabular}

Values are expressed as the mean \pm standard deviation. In comparison between groups: Difference of means, Confidence interval and p value according to Bonferroni's correction. *Indicates statistical significance $\mathrm{p}<0.05$.

Table 3. PPT over trapezius muscle. Comparison between groups

\begin{tabular}{|c|c|c|c|c|c|c|}
\hline Variable & Non-MTrP & Active-MTrP & Latent-MTrP & $\begin{array}{c}\text { Non-MTrP } \\
\text { vs } \\
\text { Active-MTrP }\end{array}$ & $\begin{array}{c}\text { Non-MTrP } \\
\text { vs } \\
\text { Latent-MTrP }\end{array}$ & $\begin{array}{c}\text { Active-MTrP } \\
\text { vs } \\
\text { Latent-MTrP }\end{array}$ \\
\hline PPT PRE & $2.83 \pm 0.95$ & $2.69 \pm 0.76$ & $2.90 \pm 0.91$ & $\begin{array}{c}0.144 \\
(-0.514-0.803) \\
1.000\end{array}$ & $\begin{array}{c}-0.067 \\
(-0.725-0.592) \\
1.000\end{array}$ & $\begin{array}{c}-0.211 \\
(-0.861-0.440) \\
1.000\end{array}$ \\
\hline PPT POST & $3.53 \pm 0.98$ & $3.44 \pm 1.27$ & $3.52 \pm 1.45$ & $\begin{array}{c}0.096 \\
(-0.843-1.034) \\
1.000\end{array}$ & $\begin{array}{c}0.008 \\
(-0.931-0.947) \\
1.000\end{array}$ & $\begin{array}{c}-0.088 \\
(-1.016-0.840) \\
1.000\end{array}$ \\
\hline
\end{tabular}

Comparison between groups: Difference of means, Confidence interval and p value according to Bonferroni's correction. *Indicates statistical significance $p<0.05$.

Table 4. PPT over tibialis muscle. Comparison between groups 


\begin{tabular}{|c|c|c|c|c|c|c|}
\hline Variable & Non-MTrP & Active-MTrP & Latent-MTrP & $\begin{array}{c}\text { Non-MTrP } \\
\text { vs } \\
\text { Active-MTrP }\end{array}$ & $\begin{array}{c}\text { Non-MTrP } \\
\text { vs } \\
\text { Latent-MTrP }\end{array}$ & $\begin{array}{c}\text { Active-MTrP } \\
\text { vs } \\
\text { Latent-MTrP }\end{array}$ \\
\hline PPT PRE & $4.92 \pm 1.13$ & $5.39 \pm 1.36$ & $6.06 \pm 1.36$ & $\begin{array}{c}-0.464 \\
(-1.435-0.506) \\
0,732\end{array}$ & $\begin{array}{c}-1.137 \\
(-2.107--0.166) \\
0.016^{*}\end{array}$ & $\begin{array}{c}-0.673 \\
(-1.632-0.286) \\
0.268 \\
\end{array}$ \\
\hline PPT POST & $5.16 \pm 1.10$ & $5.45 \pm 1.34$ & $6.23 \pm 1.33$ & $\begin{array}{c}-0.293 \\
(-1.241-0.656) \\
1.000\end{array}$ & $\begin{array}{c}-1.076 \\
(-2.025--0.127) \\
0.021^{*}\end{array}$ & $\begin{array}{c}-0.783 \\
(-1.721-0.154) \\
0.132\end{array}$ \\
\hline
\end{tabular}

Comparison between groups: Difference of means, Confidence interval and $p$ value according to Bonferroni's correction. *Indicates statistical significance $p<0.05$.

Table 5. PPT expansion. Comparison between groups

\begin{tabular}{|c|c|c|c|c|c|c|}
\hline Variable & Non-MTrP & Active-MTrP & Latent-MTrP & $\begin{array}{c}\text { Non-MTrP } \\
\text { vs } \\
\text { Active-MTrP }\end{array}$ & $\begin{array}{c}\text { Non-MTrP } \\
\text { vs } \\
\text { Latent-MTrP }\end{array}$ & $\begin{array}{l}\text { Active-MTrP } \\
\text { vs } \\
\text { Latent-MTrP }\end{array}$ \\
\hline PPT PRE & $7.76 \pm 1.87$ & $8.08 \pm 1.94$ & $8.96 \pm 1.73$ & $\begin{array}{c}-0.320 \\
(-1.708-1.068) \\
1.000\end{array}$ & $\begin{array}{c}-1.203 \\
(-2.591-0.185) \\
0.111\end{array}$ & $\begin{array}{c}-0.883 \\
(-2.255-0.488) \\
0.354\end{array}$ \\
\hline PPT POST & $8.70 \pm 1.90$ & $8.89 \pm 2.25$ & $9.77 \pm 2.08$ & $\begin{array}{c}-0.197 \\
(-1.761-1.367) \\
1.000\end{array}$ & $\begin{array}{c}-1.068 \\
(-2.632-0.496) \\
0.294\end{array}$ & $\begin{array}{c}-0.871 \\
(-2.417-0.675) \\
0.511\end{array}$ \\
\hline
\end{tabular}

Comparison between groups: Difference of means, Confidence interval and $p$ value according to Bonferroni's correction. *Indicates statistical significance $p<0.05$.

Table 6. Neck Disability Index. Comparison between groups

\begin{tabular}{|c|c|c|c|c|c|c|}
\hline Variable & Non-MTrP & Active-MTrP & Latent-MTrP & $\begin{array}{c}\text { Non-MTrP } \\
\text { vs } \\
\text { Active-MTrP }\end{array}$ & $\begin{array}{c}\text { Non-MTrP } \\
\text { vs } \\
\text { Latent-MTrP }\end{array}$ & $\begin{array}{c}\text { Active-MTrP } \\
\text { vs } \\
\text { Latent-MTrP }\end{array}$ \\
\hline NDI PRE & $21.24 \pm 13.56$ & $20.68 \pm 11.62$ & $20.59 \pm 13.01$ & $\begin{array}{c}0.556 \\
(-9.008-10.121) \\
1.000\end{array}$ & $\begin{array}{c}0.647 \\
(-8.917-10.212) \\
1.000\end{array}$ & $\begin{array}{c}0.091 \\
(-9.362-9.543) \\
1.000\end{array}$ \\
\hline NDI 1 WEEK & $10.43 \pm 7.41$ & $9.27 \pm 5.22$ & $8.55 \pm 7.02$ & $\begin{array}{c}1.156 \\
(-3.801-6.113) \\
1.000\end{array}$ & $\begin{array}{c}1.883 \\
(-3.074-6.840) \\
1.000\end{array}$ & $\begin{array}{c}0.727 \\
(-4.171-5.626) \\
0.511\end{array}$ \\
\hline NDI 1 MONTH & $4.57 \pm 3.96$ & $2.73 \pm 2.35$ & $2.73 \pm 2.80$ & $\begin{array}{c}1.844 \\
(-0.479-4.168) \\
0.166\end{array}$ & $\begin{array}{c}1.844 \\
(-0.479-4.168) \\
0.166\end{array}$ & $\begin{array}{c}-9,689 \mathrm{E}-16 \\
(-2.296-2.296) \\
1.000\end{array}$ \\
\hline
\end{tabular}

Comparison between groups: Difference of means, Confidence interval and $p$ value according to Bonferroni's correction.

*Indicates statistical significance $p<0.05$. 


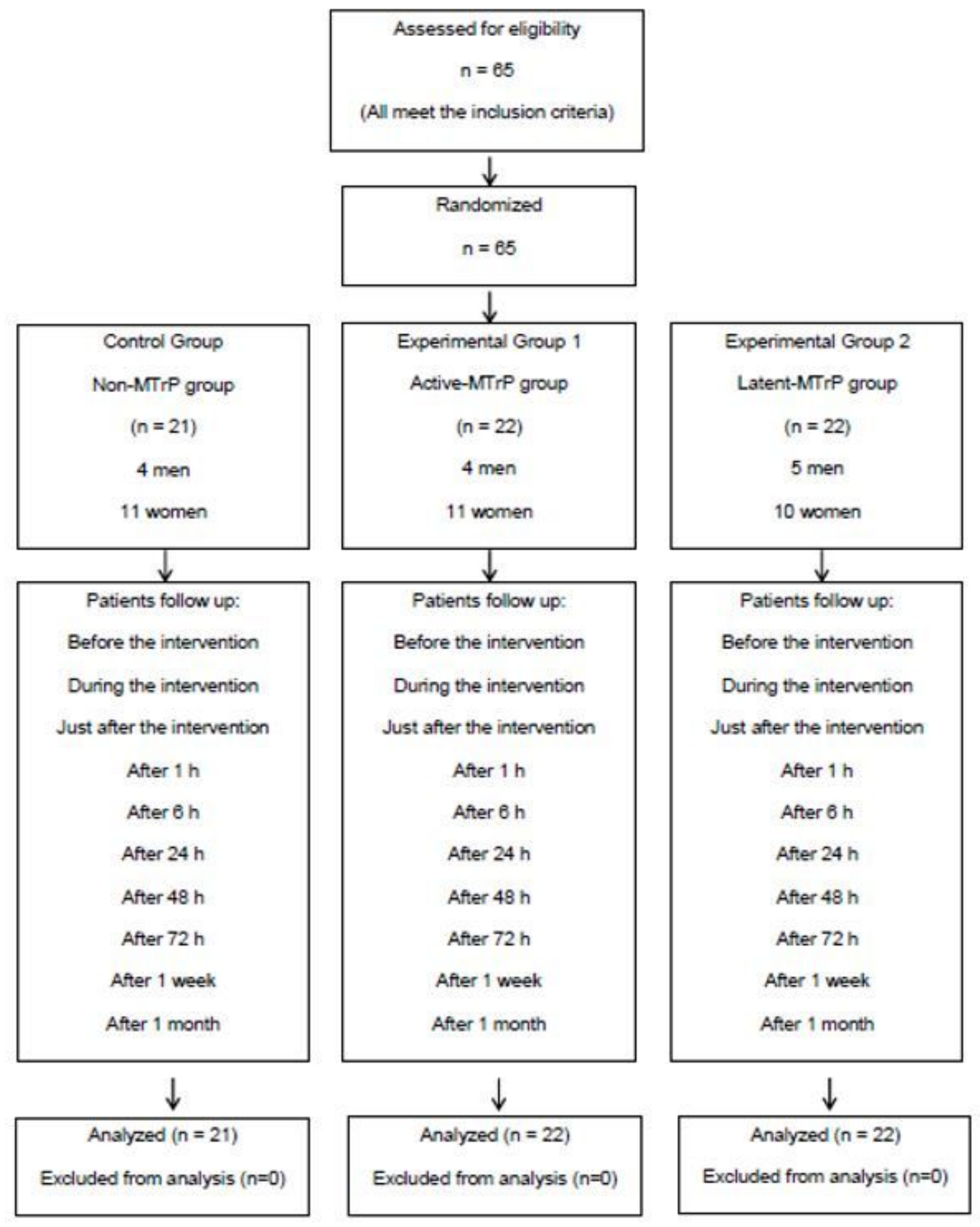

Figure 1

Flow diagram 


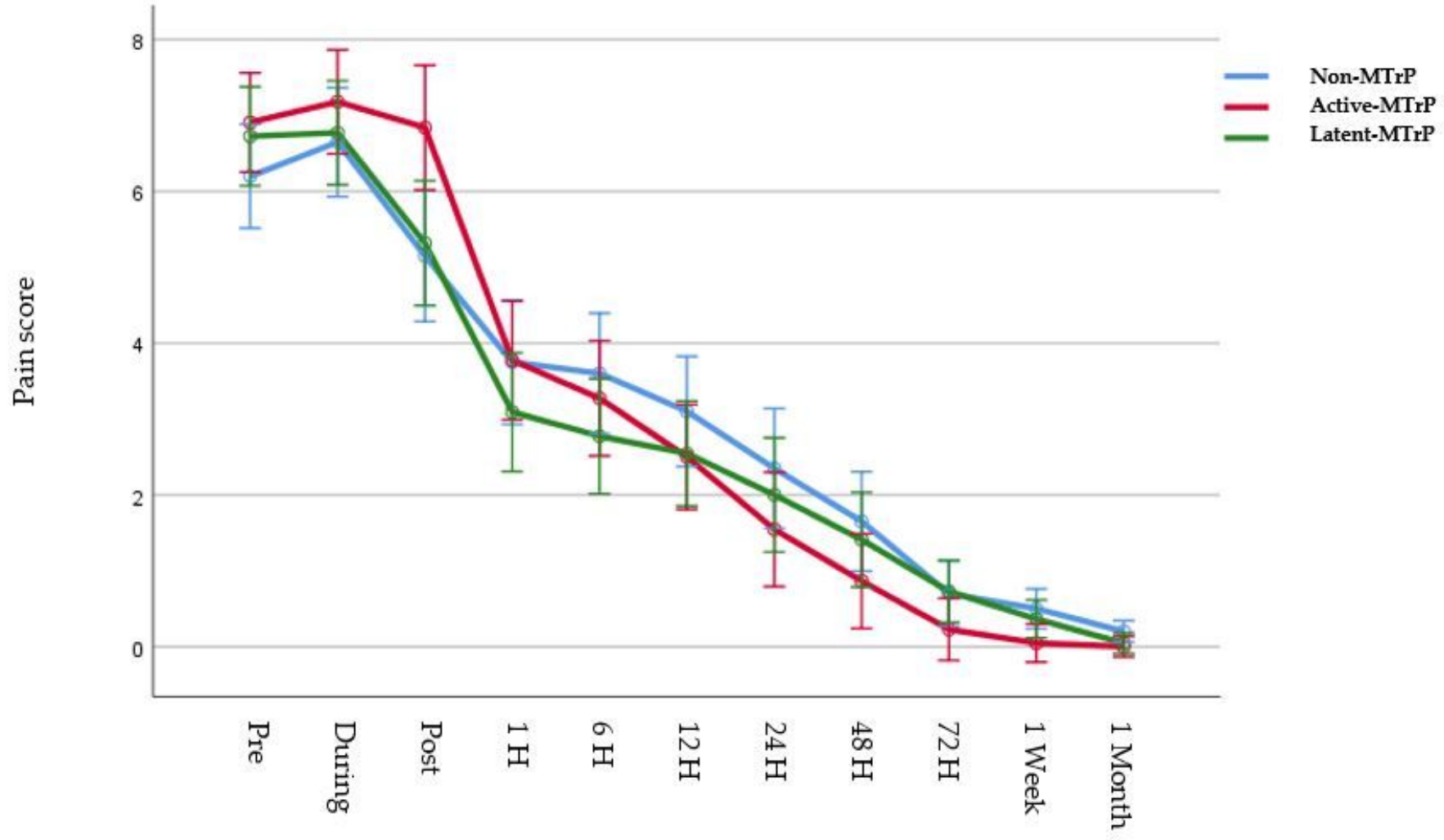

Figure 2

Pain intensity at 1 week

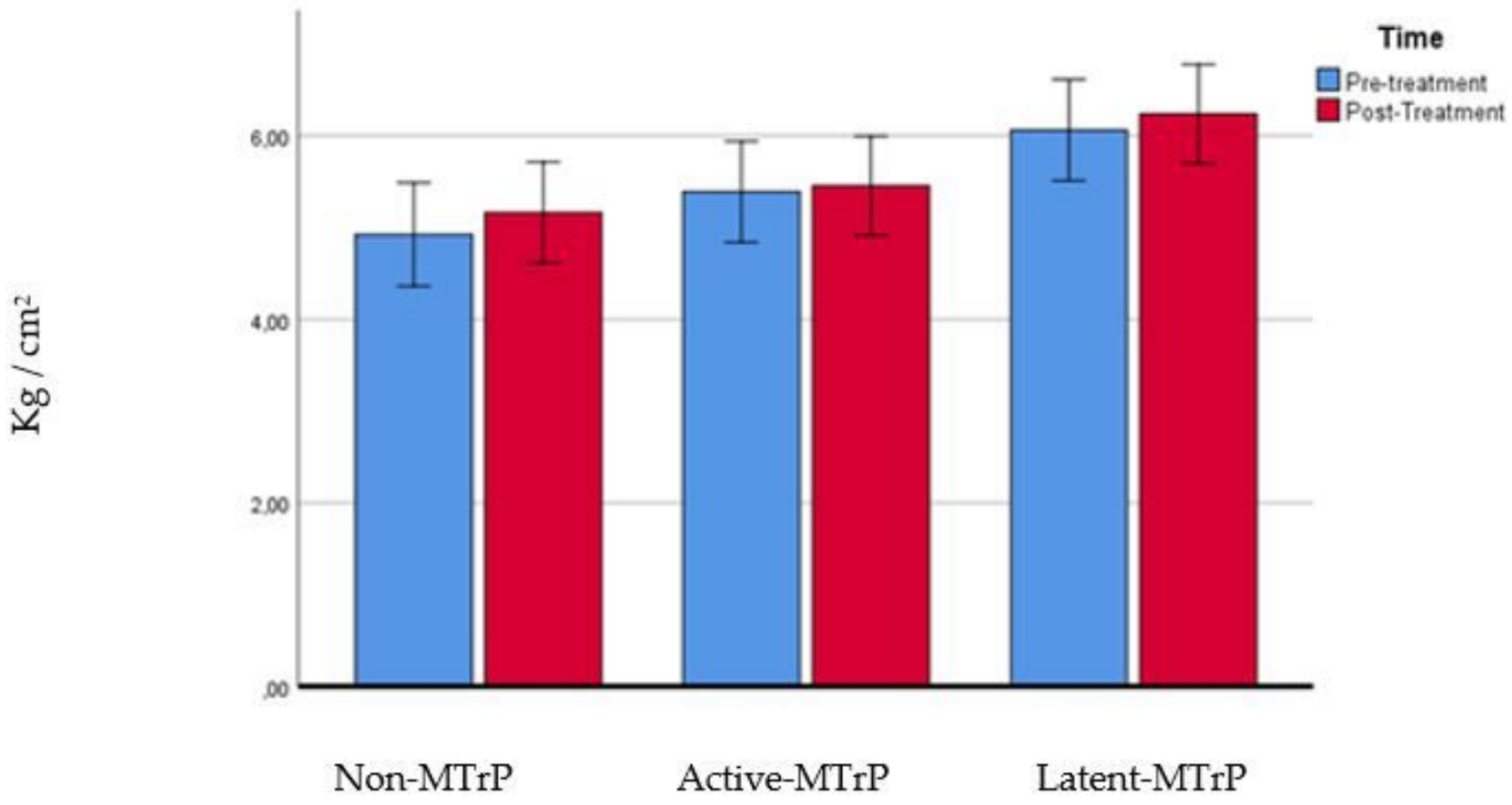


Figure 3

PPT trapezius muscle

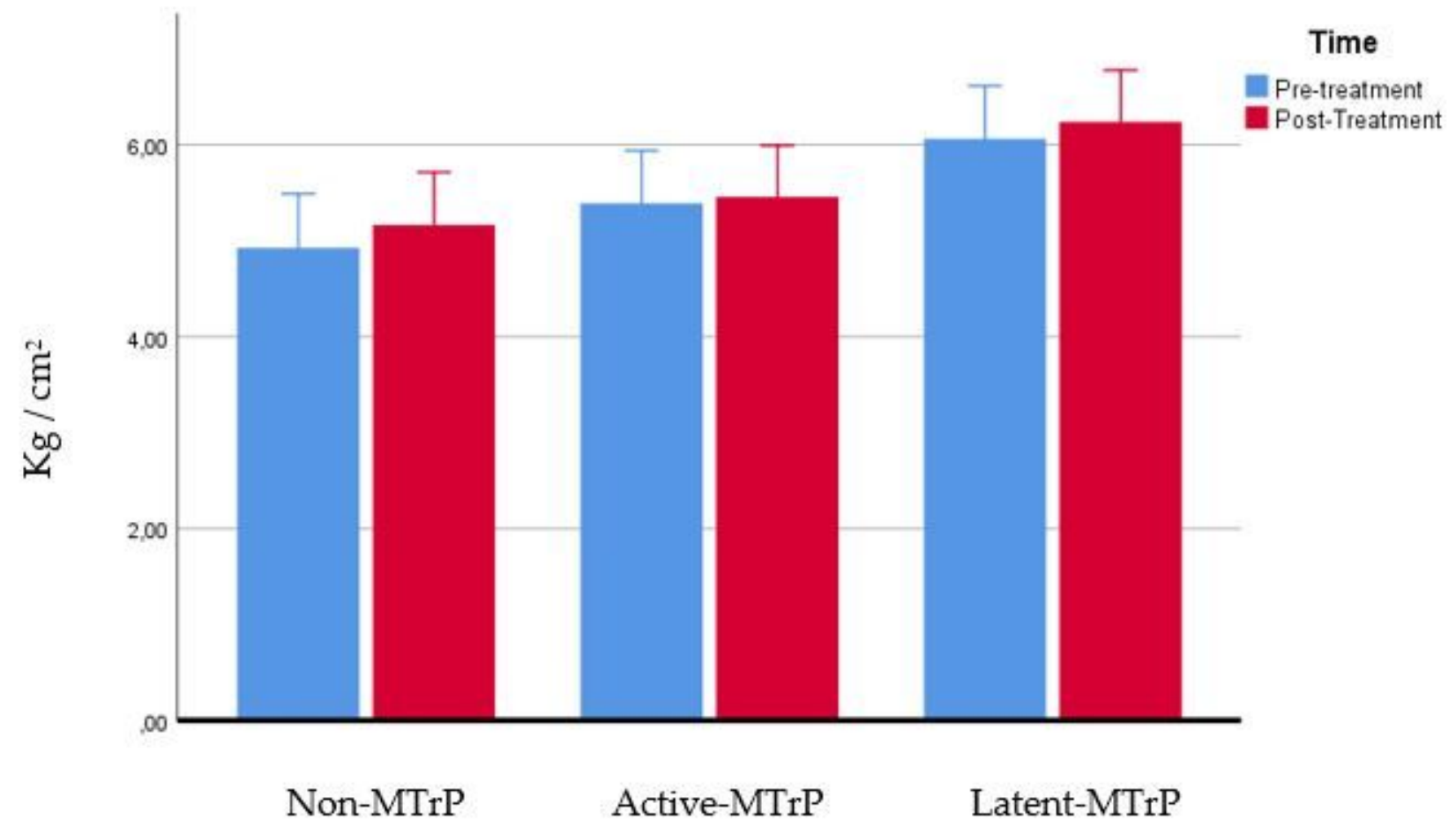

Figure 4

PPT over tibialis muscle 


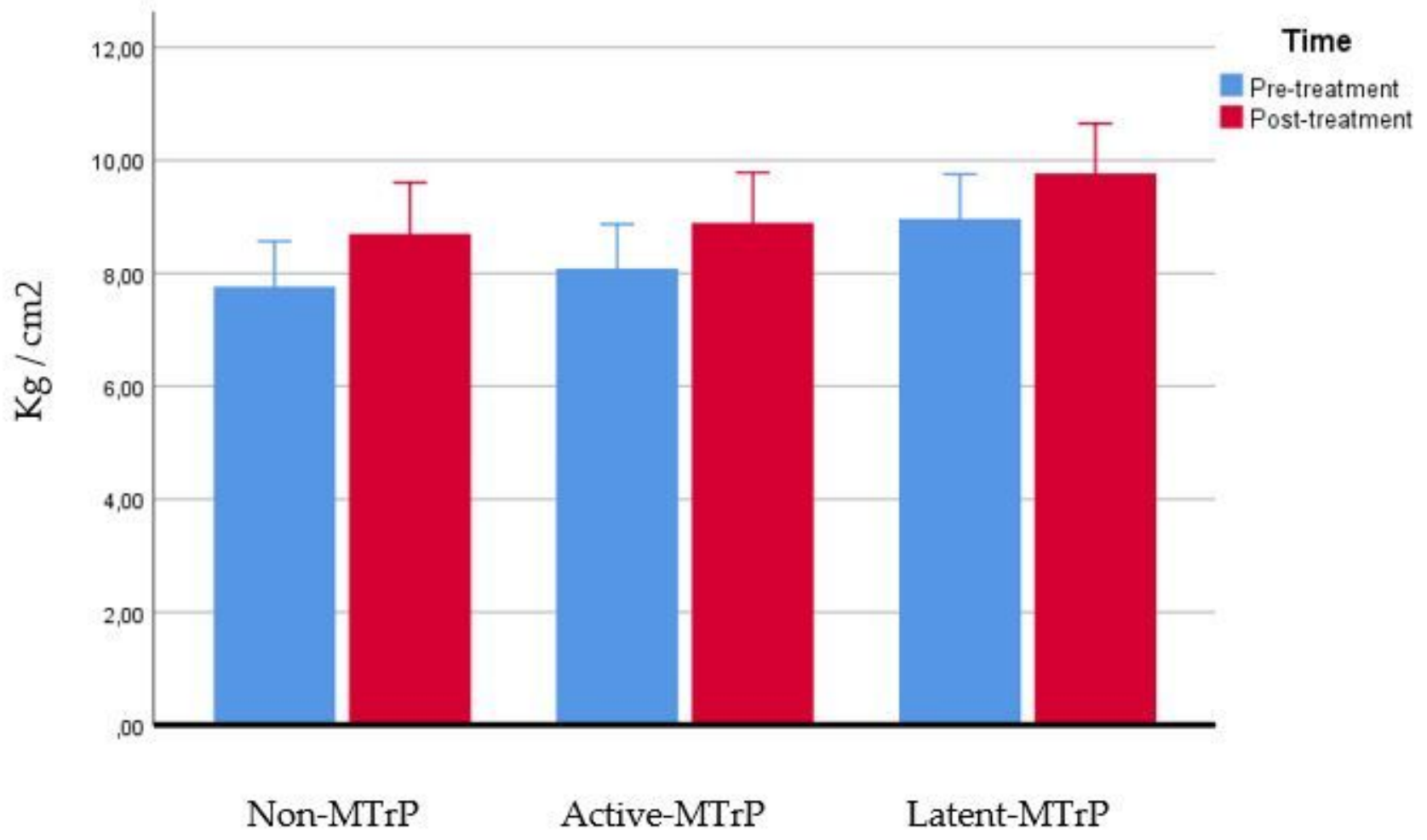

Figure 5

PPT expansion

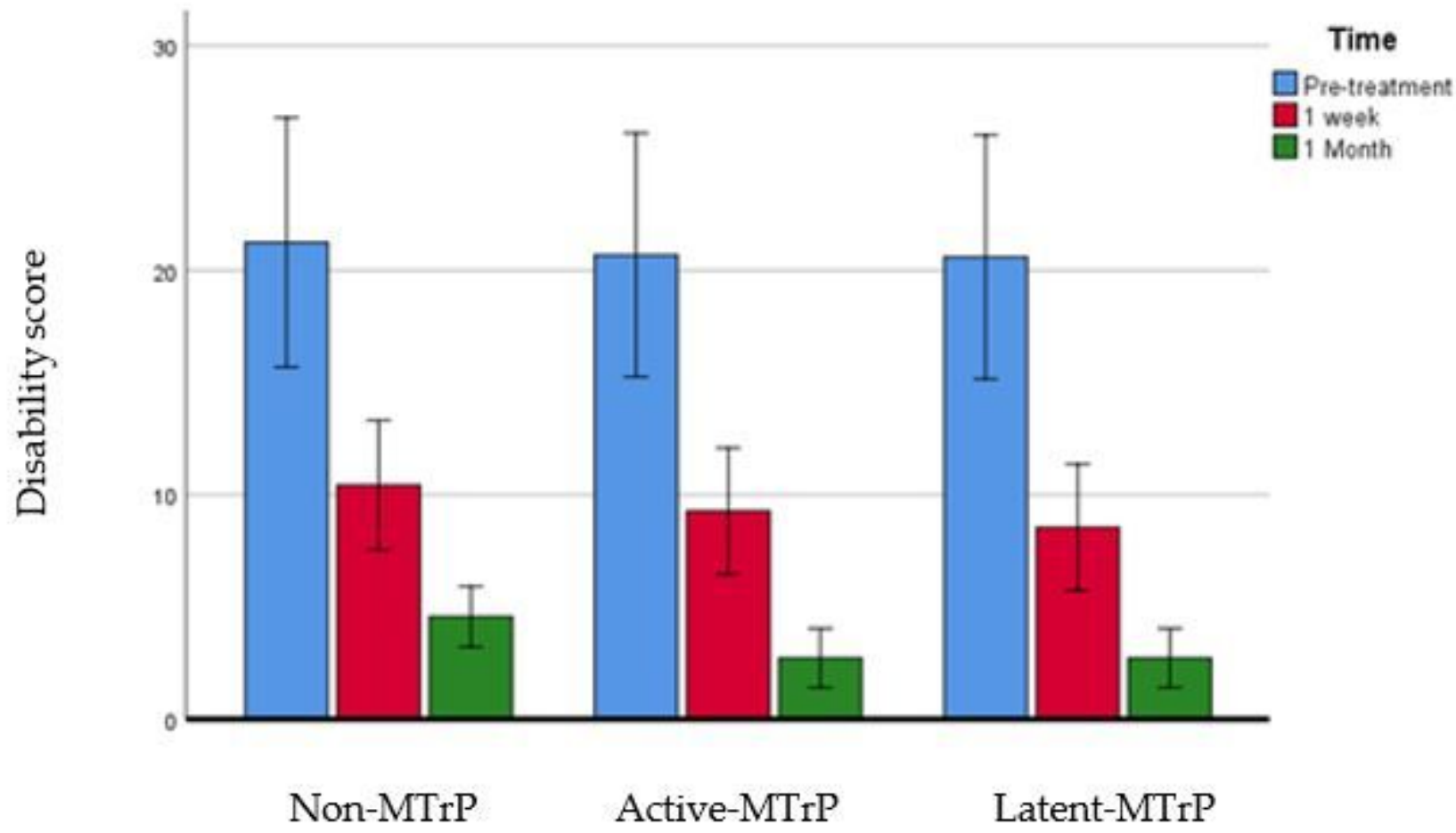

Figure 6 
Neck Disability Index

Page 26/26 